\title{
The genetic relationship between epilepsy and hemiplegic migraine
}

\author{
This article was published in the following Dove Press journal: \\ Neuropsychiatric Disease and Treatment \\ 24 April 2017 \\ Number of times this article has been viewed
}

\author{
Yiqing Huang' \\ Hai Xiaol \\ Xingyue Qin' \\ Yuan Nong' \\ Donghua Zou ${ }^{2}$ \\ Yuan $\mathrm{Wu}^{3}$ \\ 'Department of Neurology, \\ Guigang City People's Hospital \\ and the Eighth Affiliated Hospital \\ of Guangxi Medical University, \\ Guigang, People's Republic of \\ China; ${ }^{2}$ Department of Neurology, \\ The Fifth Affiliated Hospital of \\ Guangxi Medical University and the \\ First People's Hospital of Nanning, \\ Nanning, People's Republic of China; \\ ${ }^{3}$ Department of Neurology, The \\ First Affiliated Hospital of Guangxi \\ Medical University, Nanning, People's \\ Republic of China
}

\begin{abstract}
Epilepsy and migraine are common diseases of the nervous system and share genetic and pathophysiological mechanisms. Familial hemiplegic migraine is an autosomal dominant disease. It is often used as a model of migraine. Four genes often contain one or more mutations in both epilepsy and hemiplegic migraine patients (ie, CACNA1A, ATP1A2, SCN1A, and $P R R T 2)$. A better understanding of the shared genetics of epilepsy and hemiplegic migraine may reveal new strategic directions for research and treatment of both the disorders.
\end{abstract}

Keywords: epilepsy, migraine, CACNA1A, ATP1A2, SCN1A

\section{Introduction}

Epilepsy and migraine are common diseases of the nervous system. The overall prevalence of epilepsy in populations of the USA is $0.025 \%-0.05 \%$, and the prevalence of migraine in the adult population is approximately $5 \%$. Of the patients with epilepsy, $8 \%-24 \%$ also experience migraines. ${ }^{1}$ The risk of migraine in these patients is onefold greater compared with healthy controls. ${ }^{2}$ The risk of epileptic seizure in children who experience migraines is 3.2 times higher than that of children with tension headaches. ${ }^{1}$ It is possible that a headache similar to a migraine is caused by the seizure. However, there is clearly a strong association between epilepsy and migraine.

The relationship between migraine and epilepsy is not a cause-and-effect relationship. Migraine and epilepsy share the same physiological pathway. It is possible that both are caused by cortical neuron over-excitation. Epilepsy results from the synchronized discharge of neurons. Migraine is associated with cortical spreading depression (CSD), ${ }^{3}$ which is the strong depolarization of a large group of nerve cells or neuroglia that spreads to adjacent areas and inhibits neural activity., Epilepsy and migraine can spontaneously induce CSD. ${ }^{6}$ The results of animal studies have suggested that many changes that occur during CSD (eg, the increased release of glutamate, the increased concentrations of extracellular potassium ions, and the inhibition of the $\mathrm{Na}^{+} / \mathrm{K}^{+}$ATPase) are also associated with the sense of foreboding experienced by some migraine patients. ${ }^{7}$ Taken together, these results indicate that CSD may be the basis for migraine aura.

Some shared mutations have been identified in the cases of epilepsy and migraine, which suggests that there is a common genetic basis for these conditions. The two categories of migraine are migraine without aura and migraine with aura; hemiplegic migraine is a rare form of migraine with aura. Hemiplegic migraine can be subdivided into familial hemiplegic migraine (FHM) and sporadic hemiplegic migraine (SHM). FHM is a monogenic (Mendel's Laws determine the inheritance pattern) autosomal dominant disease. It is often used as a model during studies of mechanisms associated 
with migraine. This article discusses the possible common genetic basis for epilepsy and migraine.

\section{CACNAIA gene}

The CACNA1A gene is located at the gene map locus 19p13, between microsatellite markers D19S216 and D19S215. The $C A C N A 1 A$ gene encodes for the $\mathrm{Ca} 2.1 \alpha 1$ subunit. Voltagegated $\mathrm{P} / \mathrm{Q}$-type calcium channels are composed of $\alpha 1$ subunits. The subunits contain four homologous regions (I-IV); each region contains six transmembrane segments. ${ }^{8}$ The S4 segment connects to a positively charged amino acid to form the S4 transmembrane $\alpha$-helix, which acts as a "voltage sensor". The S5-S6 connecting section forms a channel hole, which selectively allows the passage of ions. ${ }^{9}$ The P/Q-type calcium channel mediates neurotransmitter release by promoting the flow of calcium to stimulate the presynaptic membrane. The specific mutations that occur in individuals with FHM type 1 are missense mutations of the $C A C N A 1 A$ gene. The mutations are often near the ion channel or in the voltage sensor. The most common mutation is T666M, which can change the current densities and gating properties. A genetic analysis of a 14-year-old girl who experienced epileptic activity during an FHM attack revealed an $1170 \mathrm{~T}$ mutation in the $C A C N A 1 A$ gene (district IV of the S5 segment). ${ }^{10} \mathrm{~S} 218 \mathrm{~L}$ knock-out mice develop severe FHM symptoms, ${ }^{11}$ and the $\mathrm{S} 218 \mathrm{~L}$ mutation (a type of CACNA1A mutation) has been identified in patients with epilepsy. ${ }^{12,13}$ Conversely, the C5733T mutation (a CACNA1A mutation) is associated with non-FHM childhood absence epilepsy. ${ }^{14}$ Genetic mutations can damage Cav2.1 channel function, which may lead to generalized seizures. ${ }^{15,16}$ Mutations in the CACNA1A gene occur in patients with epilepsy, ${ }^{17,18}$ in patients with FHM, and in patients with epilepsy and FHM as comorbid conditions. ${ }^{19}$

R192Q mutant mice can undergo a shift in the balance of excitation and inhibition in cortical neurons, ${ }^{20}$ which reduces the threshold for CSD and accelerates its propagation rate. Susceptibility to CSD is also increased in S218L mutant mice. ${ }^{11,21,22}$ A CACNA1A gene knock-in mouse model (6J-Tg) is a typical absence seizure animal model, ${ }^{23}$ we found that patients with absence seizures have a $C A C N A 1 A$ mutation. ${ }^{16,24}$ In $6 \mathrm{~J}-\mathrm{Tg}$ mice, the amino acid sequences of the S4-S5 connecting area, the S5, and part of the S5-S6 connecting region also have a high number of mutations. ${ }^{25}$ Mutations in FHM knock-in mice also occur in the S4-S5, S5, and S5-S6 connecting region, ${ }^{26}$ which suggests that $C A C N A 1 A$ gene mutations may be shared between patients with absence seizures and patients with FHM. Studies of $\mathrm{tg} / \mathrm{tg}$ mice, which have genetically linked epilepsy and may have $C A C N A 1 A$ gene mutations, revealed that loss of the CaV2.1 channel function can induce synaptic dysfunction of cortical interneurons and specifically reduce or impair the function of cortical GABA neurotransmitter. ${ }^{27}$

\section{ATPIA2 gene}

In 2003, ATP1A2 mutations were identified in families with FHM (FHM type 2, FHM2). ${ }^{28,29}$ The ATP1A2 gene is in chromosome 1q23; it codes for the $\alpha 2$ subunit of $\mathrm{Na}^{+} / \mathrm{K}^{+}$ ATPase, which consists of an $\alpha$ and a $\beta$ subunit. ATP hydrolysis releases energy and reversibly transmits three $\mathrm{Na}^{+}$into the extracellular, and two $\mathrm{K}^{+}$into the intracellular, regions. The $\alpha$ subunit includes subtypes $1-4$ and has a catalytic function. Neurons and astrocytes highly express $\alpha 2$ subunits, and in astrocytes, $\mathrm{Na}^{+} / \mathrm{K}^{+}$ATPase can regulate the extracellular $\mathrm{K}^{+}$ concentration. This regulation increases neuron excitability and induces a threshold value that can lead to CSD.

A genetic study of an Italian family with members with both hemiplegic migraine and epilepsy found that they also had the ATP1A2 mutation. ${ }^{30}$ The epilepsy incidence is increased in families with FHM2; approximately $20 \%$ experience seizures ${ }^{29}$ such as partial seizures, benign familial infantile convulsions, and high fever convulsions. In a family with FHM2, one member had partial epilepsy as a child, and electroencephalography revealed a focal migratory epilepsylike discharge waveform. The M721T and R689Q mutations of the ATP1A2 gene were found in two families with FHM2 in Holland. While patients with the R689Q mutation experienced benign familial infantile convulsions, those with the M721T mutation did not have epilepsy. ${ }^{31}$ Other studies found that the D718N and P979L mutations increase the risk for epilepsy and mental retardation. ${ }^{32}$ Similarly, the R1007W mutation may be a factor that increases susceptibility for epileptic seizures. ${ }^{33}$

Maintaining the correct concentrations of $\mathrm{Na}^{+}$and $\mathrm{K}^{+}$via the $\mathrm{Na}^{+} / \mathrm{K}^{+}$ATPase system is crucial for the ability of astrocytes to clear extracellular glutamic acid. EAAT1 also has an important role in glutamate clearance. ${ }^{34}$ The distribution of EAAT1 is consistent with that of $\mathrm{Na}^{+} / \mathrm{K}^{+}$ATPase. EAAT1 must be driven by the influx of three $\mathrm{Na}^{+}$ions and the efflux of one $\mathrm{K}^{+}$ion for glutamic acid uptake. Taken together, this evidence indicates that EAAT1 and $\mathrm{Na}^{+} / \mathrm{K}^{+}$ATPase have a close relationship in structure and physiology. ${ }^{35}$ When $\mathrm{Na}^{+} / \mathrm{K}^{+}$ ATPase function is impaired, transport of $\mathrm{K}^{+}$into the cell by astrocytes is reduced. This change results in an accumulation of $\mathrm{K}^{+}$in the extracellular fluid, which increases cell discharge frequency and excitability, and induces CSD. ${ }^{19}$ In summary, abnormal $\mathrm{Na}^{+} / \mathrm{K}^{+}$ATPase system function disrupts the $\mathrm{K}^{+}$ 
gradient and impairs glutamate clearance, which likely contributes to CSD, FHM, and epilepsy.

\section{SCNIA gene}

Dozens of mutations are associated with epilepsy. ${ }^{36}$ However, only some mutation sites are associated with FHM type 3 (FHM3). Mutation of the $S C N 1 A$ gene can result in seizures and FHM3 ${ }^{37-39}$ The SCN1A gene encodes for Nav1.1 - a voltage-gated sodium channel that is abundant in the central nervous system. Nav1.1 protein is mainly located in the cerebral cortex and spinal cord and is highly expressed in cell bodies and dendrites in these locations. SCN1A gene mutations are found in Dravet syndrome (DS) and infant idiopathic comprehensive epilepsy patients. ${ }^{40-42}$

Approximately 650 heterozygous $S C N 1 A$ mutations are found in DS patients, and the mean mutation rate is approximately $85 \%{ }^{43}$ Of these mutations, approximately $50 \%$ are nonsense mutations that result in truncated proteins and an Nav1.1 protein with only one-half of its functions (ie, one chromosome is nonfunctional). Conversely, most of the other approximately $50 \%$ of SCN1A mutations are missense mutations, which can either enhance or weaken Nav1.1 function. ${ }^{38}$ Mutations of the SCN1A gene have been found in patients with generalized epilepsy with febrile seizures plus ${ }^{44,45}$ and in patients with partial epilepsy with febrile seizures plus..$^{46,47}$ Different types of SCN1A mutations result in different effects on channel function. The Q1489K and L1649Q mutations cause FHM3, but are not associated with seizures. Conversely, a gene analysis of a Portuguese family with FHM revealed the presence of an $\mathrm{L} 263 \mathrm{~V}$ mutation; some affected family members had generalized epilepsy, and some had complex partial seizures. ${ }^{48,49}$ The L263V mutation results in a functional enhancement that accelerates recovery, thereby prolonging current duration and increasing neuron excitability. As a result, L263V mutations can result in seizures and FHM3 in the same individual. ${ }^{50}$ In contrast, mutations in Q1489K and L1649Q can inhibit neuronal functioning. ${ }^{49,51,52}$ These functional mutations can cause seizures or FHM, but not both, which suggests that an additional factor is required to promote development of the excitatory loop. ${ }^{19}$

\section{PRRT2 gene}

The CACNA1A, ATP1A2, or SCN1A genes, or some combination, can be found in approximately $75 \%$ of FHM patients and in a smaller number of SHM patients. ${ }^{53}$ The PRRT2 gene has recently been implicated in the shared pathophysiology of epilepsy and migraine. ${ }^{54}$ The PRRT2 gene is located on the 16p11.2 chromosome, contains four exons, and encodes a 340-amino acid transmembrane protein. Most study results indicate that mutations occur in the second and third exons of the PRRT2 gene. A survey of 101 patients with hemiplegic migraine (ie, 48 with FHM, 52 with SHM, and one with uncategorized hemiplegic migraine) revealed that there were no mutations of the CACNA1A, ATP1A2, or SCN1A genes. However, PRRT2 mutations were identified in four of the patients. One of these patients also had paroxysmal movement disorder and generalized seizures. ${ }^{55}$ Dale et al found that some members of an affected family experienced paroxysmal movement disorder and hemiplegic migraine. This result suggested that PRRT2 mutation was present No other hemiplegic migraine-related genes were detected. Studies have also found that PRRT2 mutations are rare in patients with hemiplegic migraine or hemiplegic migraine with paroxysmal kinesigenic dyskinesia (PKD) ${ }^{56}$ and in patients with benign familial infantile seizure (BFIS).

PRRT2 mutations are common in individuals with BFIS (ie, benign familial infantile epilepsy). BFIS is an autosomal dominant epilepsy and often occurs in infants 3-12 months of age. PRRT2 mutations are found in $80 \%$ of BFIS families, which suggests that the gene is a major cause of BFIS. ${ }^{57-59}$ PRRT2 mutation is also found in individuals with benign infantile convulsions. ${ }^{60}$ However, it is not found in infants with atypical epilepsy. This result suggests that epilepsyassociated PRRT2 mutations are specific, self-limited, and age-dependent. These characteristics may contribute to the time-dependent differences in protein expression. ${ }^{61}$

c.649dupC is a hotspot for PRRT2 mutation. c.649dupC is located at the end of a structure with eight continuous cytosine bases. This mutation causes an error in the DNA replication process that results in a truncated $P R R T 2$ protein with only 217 amino acids. Results of a yeast two-hybrid assay indicated that PRRT2 and SNAP25 interact. ${ }^{62,63}$ SNAP25 affects neurotransmitter release from the synapse and can regulate calcium channel dynamics, including for the Cav2.1 calcium channel. ${ }^{64}$ Some investigators have hypothesized that PRRT2 mutation impairs SNAP25 function, which then changes $\mathrm{CaV} 2.1$ activity, causes neuronal hyperexcitability, and results in epilepsy, hemiplegic migraine, or PKD.

\section{Conclusion}

There is a great deal of evidence suggesting that epilepsy and hemiplegic migraine have a close genetic relationship. This relationship provides a foundation for a new strategic direction for research and treatment. Epilepsy and hemiplegic migraine are disorders associated with abnormal neuronal excitability; they have overlapping regions of genetic 
inheritance. However, epilepsy occurs from the synchronous discharge of excited neurons, and abnormal neuronal excitability is transformed into CSD in migraine patients. Future studies should investigate this relationship and the different phenotypes of the two disorders.

\section{Acknowledgments}

This study was supported by the National Natural Science Foundation of China (Grant Number: 81360201), the Natural Science Foundation of Guangxi (Grant Number: 2016GXNSFCA380012), a project of the Nanning Scientific Research and Technology Development Plan (Grant Number: 20163142), and the Scientific Research Project of Guangxi Zhuang Autonomous Region Health.

\section{Author contributions}

All authors contributed toward data analysis, drafting and critically revising the paper and agree to be accountable for all aspects of the work.

\section{Disclosure}

The authors report no conflicts of interest in this work.

\section{References}

1. Toldo I, Perissinotto E, Menegazzo F, et al. Comorbidity between headache and epilepsy in a pediatric headache center. $J$ Headache Pain. 2010;11(3):235-240.

2. Haut SR, Bigal ME, Lipton RB. Chronic disorders with episodic manifestations: focus on epilepsy and migraine. Lancet Neurol. 2006; 5(2):148-157.

3. Pietrobon D, Moskowitz MA. Chaos and commotion in the wake of cortical spreading depression and spreading depolarizations. Nat Rev Neurosci. 2014;15(6):379-393.

4. Somjen GG. Mechanisms of spreading depression and hypoxic spreading depression-like depolarization. Physiol Rev. 2001;81(3):1065-1096.

5. Chang JC, Shook LL, Biag J, et al. Biphasic direct current shift, haemoglobin desaturation and neurovascular uncoupling in cortical spreading depression. Brain. 2010;133(Pt 4):996-1012.

6. Dehbandi S, Speckmann EJ, Pape HC, Gorji A. Cortical spreading depression modulates synaptic transmission of the rat lateral amygdala. Eur J Neurosci. 2008;27(8):2057-2065.

7. Kunkler PE, Hulse RE, Schmitt MW, Nicholson C, Kraig RP. Optical current source density analysis in hippocampal organotypic culture shows that spreading depression occurs with uniquely reversing currents. J Neurosci. 2005;25(15):3952-3961.

8. Neely A, Hidalgo P. Structure-function of proteins interacting with the alpha1 pore-forming subunit of high-voltage-activated calcium channels. Front Physiol. 2014;5:209.

9. Rajakulendran S, Kaski D, Hanna MG. Neuronal P/Q-type calcium channel dysfunction in inherited disorders of the CNS. Nat Rev Neurol. 2012;8(2):86-96.

10. Beauvais K, Cavé-Riant F, De Barace C, Tardieu M, TournierLasserve E, Furby A. New CACNA1A gene mutation in a case of familial hemiplegic migraine with status epilepticus. Eur Neurol. 2004;52(1): $58-61$.

11. van den Maagdenberg AM, Pietrobon D, Pizzorusso T, et al. A Cacna1a knockin migraine mouse model with increased susceptibility to cortical spreading depression. Neuron. 2004;41(5):701-710.
12. Chan YC, Burgunder JM, Wilder-Smith E, et al. Electroencephalographic changes and seizures in familial hemiplegic migraine patients with the CACNA1A gene S218L mutation. J Clin Neurosci. 2008;15(8): 891-894.

13. Vecchia D, Tottene A, van den Maagdenberg AM, Pietrobon D. Abnormal cortical synaptic transmission in CaV2.1 knockin mice with the S218L missense mutation which causes a severe familial hemiplegic migraine syndrome in humans. Front Cell Neurosci. 2015;9:8.

14. Jouvenceau A, Eunson LH, Spauschus A, et al. Human epilepsy associated with dysfunction of the brain $\mathrm{P} / \mathrm{Q}$-type calcium channel. Lancet. 2001;358(9284):801-807.

15. Rajakulendran S, Graves TD, Labrum RW, et al. Genetic and functional characterisation of the $\mathrm{P} / \mathrm{Q}$ calcium channel in episodic ataxia with epilepsy. J Physiol. 2010;588(Pt 11):1905-1913.

16. Imbrici P, Jaffe SL, Eunson LH, et al. Dysfunction of the brain calcium channel CaV2.1 in absence epilepsy and episodic ataxia. Brain. 2004;127(Pt 12):2682-2692.

17. Damaj L, Lupien-Meilleur A, Lortie A, et al. CACNA1A haploinsufficiency causes cognitive impairment, autism and epileptic encephalopathy with mild cerebellar symptoms. Eur J Hum Genet. 2015;23(11): $1505-1512$

18. Ohmori I, Ouchida M, Kobayashi K, et al. CACNA1A variants may modify the epileptic phenotype of Dravet syndrome. Neurobiol Dis. 2013; 50:209-217.

19. Rogawski MA. Migraine and epilepsy-shared mechanisms within the family of episodic disorders. In: Noebels JL, Avoli M, Rogawski MA, Olsen RW, Delgado-Escueta AV, editors. Jasper's Basic Mechanisms of the Epilepsies. Bethesda, MD: National Center for Biotechnology Information (US); 2012.

20. Inchauspe CG, Pilati N, Di Guilmi MN, et al. Familial hemiplegic migraine type-1 mutated cav2.1 calcium channels alter inhibitory and excitatory synaptic transmission in the lateral superior olive of mice. Hear Res. 2015;319:56-68.

21. Di Guilmi MN, Wang T, Inchauspe CG, et al. Synaptic gain-of-function effects of mutant Cav2.1 channels in a mouse model of familial hemiplegic migraine are due to increased basal [Ca2+]i. J Neurosci. 2014;34(21): 7047-7058.

22. Pietrobon D. Calcium channels and migraine. Biochim Biophys Acta. 2013;1828(7):1655-1665

23. Kim TY, Maki T, Zhou Y, et al. Absence-like seizures and their pharmacological profile in tottering-6j mice. Biochem Biophys Res Commun. 2015;463(1-2):148-153.

24. Gambardella A, Labate A. The role of calcium channel mutations in human epilepsy. Prog Brain Res. 2014;213:87-96.

25. Miki T, Zwingman TA, Wakamori M, et al. Two novel alleles of tottering with distinct $\mathrm{Ca}(\mathrm{v}) 2.1$ calcium channel neuropathologies. Neuroscience. 2008;155(1):31-44.

26. Pietrobon D. CaV2.1 channelopathies. Pflugers Arch. 2010;460(2): 375-393.

27. Rossignol E, Kruglikov I, van den Maagdenberg AM, Rudy B, Fishell G. CaV 2.1 ablation in cortical interneurons selectively impairs fast-spiking basket cells and causes generalized seizures. Ann Neurol. 2013;74(2):209-222.

28. Carreño O, Corominas R, Serra SA, et al. Screening of CACNA1A and ATP1A2 genes in hemiplegic migraine: clinical, genetic, and functional studies. Mol Genet Genomic Med. 2013;1(4):206-222.

29. De Fusco M, Marconi R, Silvestri L, et al. Haploinsufficiency of ATP1A2 encoding the $\mathrm{Na}+\mathrm{K}+$ pump alpha2 subunit associated with familial hemiplegic migraine type 2. Nat Genet. 2003;33(2):192-196.

30. Costa C, Prontera P, Sarchielli P, et al. A novel ATP1A2 gene mutation in familial hemiplegic migraine and epilepsy. Cephalalgia. 2014;34(1): 68-72.

31. Vanmolkot KR, Kors EE, Hottenga JJ, et al. Novel mutations in the $\mathrm{Na}+$, $\mathrm{K}+$-ATPase pump gene ATP1A2 associated with familial hemiplegic migraine and benign familial infantile convulsions. Ann Neurol. 2003; 54(3):360-366. 
32. Jurkat-Rott K, Freilinger T, Dreier JP, et al. Variability of familial hemiplegic migraine with novel A1A2 Na+/K+-ATPase variants. Neurology. 2004;62(10):1857-1861.

33. Pisano T, Spiller S, Mei D, et al. Functional characterization of a novel C-terminal ATP1A2 mutation causing hemiplegic migraine and epilepsy. Cephalalgia. 2013;33(16):1302-1310.

34. Benarroch EE. Na+, K+-ATPase: functions in the nervous system and involvement in neurologic disease. Neurology. 2011;76(3):287-293.

35. Rose EM, Koo JC, Antflick JE, Ahmed SM, Angers S, Hampson DR. Glutamate transporter coupling to Na, K-ATPase. J Neurosci. 2009; 29(25):8143-8155.

36. Fujiwara T, Sugawara T, Mazaki-Miyazaki E, et al. Mutations of sodium channel alpha subunit type 1 (SCN1A) in intractable childhood epilepsies with frequent generalized tonic-clonic seizures. Brain. 2003; 126(Pt 3):531-546.

37. Bechi G, Rusconi R, Cestele S, Striano P, Franceschetti S, Mantegazza M. Rescuable folding defective NaV1.1 (SCN1A) mutants in epilepsy: properties, occurrence, and novel rescuing strategy with peptides targeted to the endoplasmic reticulum. Neurobiol Dis. 2015;75: $100-114$.

38. Mulley JC, Scheffer IE, Petrou S, Dibbens LM, Berkovic SF, Harkin LA. SCN1A mutations and epilepsy. Hum Mutat. 2005;25(6):535-542.

39. Cestèle S, Schiavon E, Rusconi R, Franceschetti S, Mantegazza M. Nonfunctional NaV1.1 familial hemiplegic migraine mutant transformed into gain of function by partial rescue of folding defects. Proc Natl Acad Sci U S A. 2013;110(43):17546-17551.

40. Bechi G, Scalmani P, Schiavon E, Rusconi R, Franceschetti S, Mantegazza M. Pure haploinsufficiency for Dravet syndrome $\mathrm{Na}(\mathrm{V}) 1.1$ (SCN1A) sodium channel truncating mutations. Epilepsia. 2012;53(1): 87-100.

41. Claes L, Del-Favero J, Ceulemans B, Lagae L, Van Broeckhoven C, De Jonghe P. De novo mutations in the sodium-channel gene SCN1A cause severe myoclonic epilepsy of infancy. Am J Hum Genet. 2001; 68(6):1327-1332.

42. Guerrini R, Marini C, Mantegazza M. Genetic epilepsy syndromes without structural brain abnormalities: clinical features and experimental models. Neurotherapeutics. 2014;11(2):269-285.

43. Meisler MH, Kearney JA. Sodium channel mutations in epilepsy and other neurological disorders. J Clin Invest. 2005;115(8):2010-2017.

44. Escayg A, MacDonald BT, Meisler MH, et al. Mutations of SCN1A, encoding a neuronal sodium channel, in two families with GEFS+2. Nat Genet. 2000;24(4):343-345.

45. Kasperaviciute D, Catarino CB, Matarin M, et al. Epilepsy, hippocampal sclerosis and febrile seizures linked by common genetic variation around SCN1A. Brain. 2013;136(Pt 10):3140-3150.

46. Catterall WA. Sodium channels, inherited epilepsy, and antiepileptic drugs. Annu Rev Pharmacol Toxicol. 2014;54:317-338.

47. Liao WP, Shi YW, Long YS, et al. Partial epilepsy with antecedent febrile seizures and seizure aggravation by antiepileptic drugs: associated with loss of function of $\mathrm{Na}(\mathrm{v})$ 1.1. Epilepsia. 2010;51(9):1669-1678.
48. Castro MJ, Stam AH, Lemos C, et al. First mutation in the voltage-gated Nav1.1 subunit gene SCN1A with co-occurring familial hemiplegic migraine and epilepsy. Cephalalgia. 2009;29(3):308-313.

49. Kahlig KM, Lepist I, Leung K, Rajamani S, George AL. Ranolazine selectively blocks persistent current evoked by epilepsy-associated Nav1.1 mutations. Br J Pharmacol. 2010;161(6):1414-1426.

50. Barros J, Ferreira A, Brandão AF, et al. Familial hemiplegic migraine due to L263V SCN1A mutation: discordance for epilepsy between two kindreds from Douro Valley. Cephalalgia. 2014;34(12):1015-1020.

51. Escayg A, Goldin AL. Sodium channel SCN1A and epilepsy: mutations and mechanisms. Epilepsia. 2010;51(9):1650-1658.

52. Hedrich UB, Liautard C, Kirschenbaum D, et al. Impaired action potential initiation in GABAergic interneurons causes hyperexcitable networks in an epileptic mouse model carrying a human $\mathrm{Na}(\mathrm{V}) 1.1$ mutation. J Neurosci. 2014;34(45):14874-14889.

53. Russell MB, Ducros A. Sporadic and familial hemiplegic migraine: pathophysiological mechanisms, clinical characteristics, diagnosis, and management. Lancet Neurol. 2011;10(5):457-470.

54. Gardiner AR, Bhatia KP, Stamelou M, et al. PRRT2 gene mutations: from paroxysmal dyskinesia to episodic ataxia and hemiplegic migraine. Neurology. 2012;79(21):2115-2121.

55. Riant F, Roze E, Barbance C, et al. PRRT2 mutations cause hemiplegic migraine. Neurology. 2012;79(21):2122-2124.

56. Wang JL, Cao L, Li XH, et al. Identification of PRRT2 as the causative gene of paroxysmal kinesigenic dyskinesias. Brain. 2011;134(Pt 12): 3493-3501.

57. de Vries B, Callenbach PM, Kamphorst JT, et al. PRRT2 mutation causes benign familial infantile convulsions. Neurology. 2012;79: 2154-2155.

58. Heron SE, Grinton BE, Kivity S, et al. PRRT2 mutations cause benign familial infantile epilepsy and infantile convulsions with choreoathetosis syndrome. Am J Hum Genet. 2012;90(1):152-160.

59. Nobile C, Striano P. PRRT2: a major cause of infantile epilepsy and other paroxysmal disorders of childhood. Prog Brain Res. 2014;213: 141-158.

60. Marini C, Conti V, Mei D, et al. PRRT2 mutations in familial infantile seizures, paroxysmal dyskinesia, and hemiplegic migraine. Neurology. 2012;79(21):2109-2114.

61. Chen WJ, Lin Y, Xiong ZQ, et al. Exome sequencing identifies truncating mutations in PRRT2 that cause paroxysmal kinesigenic dyskinesia. Nat Genet. 2011;43(12):1252-1255.

62. Lee HY, Huang Y, Bruneau N, et al. Mutations in the gene PRRT2 cause paroxysmal kinesigenic dyskinesia with infantile convulsions. Cell Rep. 2012;1(1):2-12.

63. Stelzl U, Worm U, Lalowski M, et al. A human protein-protein interaction network: a resource for annotating the proteome. Cell. 2005; 122(6):957-968.

64. Cohen-Kutner M, Nachmanni D, Atlas D. CaV2.1 (P/Q channel) interaction with synaptic proteins is essential for depolarization-evoked release. Channels (Austin). 2010;4(4):266-277.
Neuropsychiatric Disease and Treatment

\section{Publish your work in this journal}

Neuropsychiatric Disease and Treatment is an international, peerreviewed journal of clinical therapeutics and pharmacology focusing on concise rapid reporting of clinical or pre-clinical studies on a range of neuropsychiatric and neurological disorders. This journal is indexed on PubMed Central, the 'PsycINFO' database and CAS,

\section{Dovepress}

and is the official journal of The International Neuropsychiatric Association (INA). The manuscript management system is completely online and includes a very quick and fair peer-review system, which is all easy to use. Visit http://www.dovepress.com/testimonials.php to read real quotes from published authors. 